\title{
DIMENSI SOCIAL CAPITAL YANG MEMENGARUHI KINERJA PEGAWAI BPJS KESEHATAN
}

\author{
Social Capital Dimensions Influencing Staff Performance \\ in Health BPJS
}

\author{
Muhammad Tahajjudi Ghifary \\ Program Studi S2 Pengembangan SDM, Sekolah Pascasarjana UNAIR \\ (ghifary.one@gmail.com)
}

\begin{abstract}
ABSTRAK
Social capital dipandang dari perspektif sumber daya manusia merupakan upaya mengelola sumber daya menjadi aspek penting dalam pembentukan organisasi. Social capital didefinisikan sebagai serangkaian sumber daya potensial dan aktual yang tersedia pada jejaring organisasi yang dikembangkan oleh individu maupun kelompok. Tujuan penelitian mengkaji tingkat keterpengaruhan structural relational dan cognitive social capital terhadap kinerja pegawai BPJS Kesehatan Cabang Pasuruan. Rancangan penelitian bersifat kuantitatif, serta menggunakan pendekatan cross sectional dengan sampel sebanyak 52 responden yang merupakan total populasi. Data dikumpulkan melalui pengisian kuesioner. Variabel-variabel diuji dengan menggunakan uji regresi linier sederhana dan berganda. Diperoleh temuan bahwa structural social capital, relational social capital maupun cognitive social capital secara terpisah mempunyai pengaruh yang positif terhadap kinerja pegawai BPJS Kesehatan Cabang Pasuruan. Interaksi sosial, tingkat kepercayaan serta kesamaan dalam mengartikan visi perusahaan dipandang merupakan aspek yang dapat mewarnai kinerja pegawai. Ketika ketiga dimensi ini disatukan (unidimensi) masih tampak adanya pengaruh terhadap kinerja pegawai. Namun, manakala ketiga dimensi social capital tersebut diperlakukan secara multidimensi tidak diperoleh hasil keterpengaruhan yang signifikan. Social capital sebagai satu kesatuan tidak dapat diposisikan pada dimensinya masing-masing, tetapi harus diletakkan sebagai sebuah kerangka dimensi yang utuh.
\end{abstract}

Kata kunci : Pengembangan SDM, social capital, kinerja pegawai

ABSTRACT

From the perspective of human resources, social capitalis seen asan effort to manage resources, which is an important aspect in the formation of an organization. Social capital is defined as a number of potential and actual resources that are available from the organization network developed by an individual or group. The purpose of this study was to assess the level of influence of structural relational and cognitive social capital on staff performance in the Health care BPJS (Social Security Administrative Body) of Pasuruan Branch. A quantitative design was adopted with a cross-sectional approach. The sample size was 52 respondents which is the total population. Data were collected through questionnaires. Variables were tested using simple and multiple linear regression. It was found that separately, structural social capital, relational social capital, and cognitive social capital have a positive influence on staff performance. Social interaction, the level of trust, and similarity in interpreting the company's vision are factors that could influence staff performance. When these three dimensions are united (dimensional unity), influence on staff performance was still found. However, when the three social capital dimensions were treated multidimensionally, no significant influence was found. Social capital as a unity can't be positioned on each of it's dimensions, but must be positioned as a whole dimension framework.

Keywords : Human resource development, social capital, staff performance 


\section{PENDTAHULUAN}

Sumber daya manusia menjadi begitu penting untuk para pemimpin bisnis karena secara nyata telah memperlihatkan keunggulan kompetitif berkelanjutan yang terwujud dalam bentuk human capital. ${ }^{1}$ Seturut dengan itu, social capital muncul sebagai kepanjangan dari human capital. Social capital dianggap memiliki potensi untuk menerjemahkan ke dalam produktivitas kerja, khususnya yang mengacu pada hubungan sosial. ${ }^{2}$

Social capital dapat dimaknai sebagai salah satu potensi sumber daya yang dapat dimanfaatkan oleh seseorang di samping sumber daya lainnya seperti modal manusia dan budaya (keterampilan dan keahlian), modal fisik (alat bantu) dan modal ekonomi (uang). ${ }^{3}$ Social capital dinyatakan dalam bentuk kesamaan keyakinan serta nilai-nilai dan hubungan sosial di antara anggota organisasi, dapat diasumsikan bahwa tidak hanya individu, tetapi juga organisasi yang kompleks seperti unit pelayanan terkait kesehatan yang memiliki social capital. Suasana yang berhasil dibangun atas dasar kepercayaan, kesamaan nilai serta keyakinan dapat membantu orang bekerjasama dan membuatnya lebih mudah bagi mereka untuk menilai kondisi kerjanya sehari-hari dengan mengurangi ketidakamanan, ketidakpastian dan disorientasi. ${ }^{4}$

Mengacu pada UU Nomor 24 Tahun 2011 tentang Badan Penyelenggara Jaminan Sosial (BPJS), PT Askes (Persero) yang sebelumnya mengelola jaminan kesehatan bagi pegawai negeri sipil dan pensiunan ditransformasikan menjadi BPJS Kesehatan sebagai penyelenggara program jaminan kesehatan bagi seluruh rakyat Indonesia. Mencermati beban keorganisasian pada masamasa awal operasionalisasi BPJS Kesehatan, tidak hanya di tingkat pusat maupun regional, tetapi juga di tingkat cabang seperti Cabang Pasuruan, niscaya dibutuhkan upaya pengembangan sumber daya manusia. Selain human capital, peran social capital dalam kaitan ini juga dipandang sangat menentukan, karena social capital tertanam dalam hubungan antar individu. Social capital meliputi beragam aspek struktur sosial yang menyediakan kemudahan untuk para aktor secara individu maupun kelompok. ${ }^{5}$

Adapun kinerja dapat dimaknai sebagai pencapaian tugas tertentu yang terukur berdasarkan standar yang telah ditetapkan atau diidentifikasi keakurasian, kelengkapan, pembiayaan dan kecepatannya ${ }^{6}$ Kinerja adalah hasil kerja yang dicapai oleh seseorang atau kelompok dalam organisasi, sesuai dengan wewenang dan tanggung jawab, dalam upaya untuk mencapai tujuan organisasi secara legal, tidak melanggar hukum, dan sesuai dengan moral dan etika. ${ }^{7}$

Penelitian ini mengacu pada pendekatan yang mengedepankan keterpengaruhan dimensi-dimensi social capital (structural, relational dan cognitive) terhadap kinerja individu dari $\mathrm{Na}-$ hapiet dan Ghoshal. ${ }^{8}$ Dimensi structural melibatkan interaksi sosial yang digunakan oleh aktor untuk mendapatkan akses, informasi, ataupun sumber daya. Dimensi relational mencakup aspek yang muncul dari terjadinya interaksi, termasuk kepercayaan dan loyalitas. Dimensi cognitive meliputi atribut seperti norma-norma bersama, kode tindakan, dan konvergensi dari pandangan. ${ }^{9}$

Tujuan penelitian ini menggali keterpengaruhan dimensi social capital terhadap kinerja pegawai pada BPJS Kesehatan Cabang Pasuruan. Secara khusus maksud penelitian ini mengkaji pengaruh positif antara dimensi structural, relational dan cognitive pada social capital dengan kinerja pegawai. Di samping itu juga untuk mengkaji perbedaan pengaruh di antara dimensi-dimensi social capital dimaksud terhadap kinerja pegawai manakala diperlakukan dalam bentuk unidimensi dan multidimensi.

\section{BAHAN DAN METODE}

Jenis rancangan penelitian ini adalah penelitian kuantitatif dengan pendekatan studi cross sectional karena pengambilan datanya satu per satu pada satu titik waktu. ${ }^{10}$ Penelitian dilaksanakan pada bulan Juni hingga September 2015 dengan mengambil lokasi pada BPJS Kesehatan Cabang Pasuruan.Wilayah kerja institusi ini meliputi Kota Pasuruan, Kabupaten Pasuruan, Kota Probolinggo dan Kabupaten Probolinggo. Jumlah seluruh pegawai pada instansi tersebut adalah sebanyak 52 orang. Oleh karena jumlah populasi yang tidak terlalu banyak, maka jumlah sampel sama dengan jumlah populasi, sehingga teknik sampling yang digunakan adalah non-probability sampling. ${ }^{10}$

Data-data dalam penelitian ini bersumber dari data primer dan sekunder. Data primer didapatkan dari jawaban pegawai BPJS Kesehatan 
Cabang Pasuruan atas kuesioner yang dibagikan, sedangkan data sekunder adalah data terkait profil badan usaha, sumber daya manusia dan data pendukung lainnya. Data dianalisis dengan menggunakan uji Regresi Linear, sehingga dapat diketahui kekuatan pengaruh dan arah hubungan antara variabel independen berupa variabel social capital structural, relational dan cognitive dengan variabel dependen yakni kinerja pegawai. ${ }^{11}$ Sementara untuk mengetahui arah dan nilai hubungan antar dua atau lebih variabel independen dengan satu variabel dependen dilakukan uji Regresi Berganda. ${ }^{12}$

\section{HASIL}

Karakteristik pegawai BPJS Kesehatan Cabang Pasuruan diperoleh dari data primer berupa komposisi usia responden terbanyak terletak pada interval usia 27-30 tahun sebesar 32,7\%. Jumlah yang berbeda yaitu sebesar $26,9 \%$ juga terdapat pada 31-34 tahun dengan jumlah responden sebanyak 14 orang, sedangkan interval usia 19-22 tahun, usia 35-38 tahun, usia 47-50 tahun dan usia 51-54 tahun masing-masing memiliki jumlah yang sama yakni sebanyak 5,8\% atau hanya terdapat 3 responden pada setap interval usia. Adapun sisanya sejumlah $17,3 \%$ terdapat pada interval usia 23-26 tahun.

Data tersebut dapat diperjelas lagi dengan kriteria komposisi usia pegawai pada setiap unit kerja. Diketahui bahwa pada unit pemasaran terdapat 5 pegawai dengan masing-masing ada yang berada pada interval usia 23-26 tahun, 27-30 ta-

Tabel 1. Karakteristik Responden

\begin{tabular}{lcc}
\hline \multicolumn{1}{c}{ Karakteristik } & $\mathbf{n}=\mathbf{5 2}$ & $\mathbf{\%}$ \\
\hline Masa Kerja Pegawai (tahun) & & \\
$0-4$ & 37 & 71,2 \\
$5-8$ & 6 & 11,5 \\
$9-12$ & 3 & 5,8 \\
$13-16$ & 1 & 1,9 \\
$17-20$ & 4 & 7,7 \\
$29-32$ & 1 & 1,9 \\
Tingkat Pendidikan Pegawai & & \\
Setingkat SLTP & 2 & 3,8 \\
Setingkat SLTA & 7 & 13,5 \\
Diploma & 12 & 23,1 \\
Sarjana & 30 & 57,7 \\
Pascasarjana & 1 & 1,9 \\
\hline
\end{tabular}

Sumber : Data Primer, 2015 hun, 31-34 tahun dan yang paling senior berada pada interval usia 47-50 tahun. Berbeda dengan unit pemasaran, pada unit keuangan, umum dan teknologi informasi terdapat lebih banyak pegawai yaitu sebesar 18 orang pegawai. Sebanyak 7 orang pegawai berada pada interval usia 27-30 tahun, sedangkan yang paling sedikit yaitu hanya seorang pegawai berada pada interval 47-50 tahun.

Pada unit manajemen pelayanan kesehatan primer yang jumlah pegawainya hanya 5 orang komposisinya adalah 2 orang berada pada interval usia 27-30 tahun. Jumlah yang sama juga terdapat pada interval usia 31-34 tahun, selebihnya terdapat pada interval usia 23-36 tahun. Pada unit kepesertaan dan pelayanan peserta, sejumlah 7 orang pegawai terdapat pada interval 23-26 tahun. Adapun 7 orang pegawai berikutnya berada pada interval usia 31-34 tahun. Sisanya sebanyak 5 orang pegawai terbagi rata pada seluruh interval usia yang ada. Hal yang unik terjadi pada unit manajemen pelayanan kesehatan rujukan, yaitu pegawainya hanya 5 orang dengan interval usia yang sama yakni 27-30 tahun.

Jenis kelamin pegawai BPJS Kesehatan Cabang Pasuruan memiliki jumlah yang hampir seimbang yaitu 51,9\% untuk laki-laki dan $48,1 \%$ untuk perempuan. Akan tetapi jika dilihat dari setiap unit kerja yang ada hasilnya tidaklah selalu sebanding. Pada unit pemasaran yang hanya terdapat 5 orang pegawai dari keseluruhan pegawai, terdapat jenis kelamin laki-laki sejumlah 7,7\% dan perempuan sebanyak $1,9 \%$. Pada unit manajemen pelayanan kesehatan rujukan justru kondisinya berbeda. Komposisi pegawai perempuan memiliki angka 9,6\% dari keseluruhan pegawai, akan tetapi jenis kelamin laki-laki presentasenya $0 \%$. Kondisi yang hampir seimbang terdapat pada unit kepesertaan dan pelayanan peserta yaitu sebanyak $19,2 \%$ berjenis kelamin laki-laki dan sisanya sebanyak $17,3 \%$ berjenis kelamin perempuan.

Selain usia dan jenis kelamin, lamanya masa kerja pegawai BPJS Kesehatan Cabang Pasuruan juga merupakan salah satu hal yang harus diperhatikan. Kebanyakan pegawai mempunyai masa kerja yang relatif baru yaitu 0-4 tahun. Hal ini ditunjukkan dengan $71,2 \%$ pegawai memiliki masa kerja dimaksud. Sedangkan $11,5 \%$ pegawai mempunyai masa kerja 5-8 tahun. Kemudian terdapat $7,7 \%$ pegawai yang memiliki masa kerja 
17-20 tahun. Sementara masa kerja pegawai 9-12 tahun memiliki presentase sebesar 5,8\%. Untuk masa kerja pegawai 13-16 tahun dan 29-32 tahun masing-masing hanya terdapat 1,9\% (Tabel 1).

Terdapat lima unit kerja pada BPJS Kesehatan Cabang Pasuruan. Dengan banyaknya unit kerja dan pegawai maka diperlukan sebuah kegiatan supervisi pegawai agar dapat menjalankan visi, misi dan tujuan perusahaan dengan baik. Kenyataan ini telah dilakukan dengan seksama oleh BPJS Kesehatan Cabang Pasuruan. Hal ini ditunjukkan dengan adanya beberapa pegawai yang melakukan kegiatan supervisi kepada pegawai lain. Terdapat 7 (tujuh) orang pegawai yang melakukan kegiatan supervisi. Pada masing-masing unit kerja terdapat 1 (satu) orang pegawai yang melakukan tugas tersebut. Hal yang berbeda terdapat pada unit keuangan, umum dan teknologi informasi yang menugaskan 3 orang pegawainya untuk melakukan supervisi terhadap pegawai lain.

Tingkat pendidikan pegawai pada BPJS Kesehatan Cabang Pasuruan merupakan aspek yang patut dicermati. Lebih dari separuh atau sebanyak $57,7 \%$ pegawai berlatar belakang pendidikan sarjana. Sedangkan pegawai dengan latar belakang pascasarjana sangat sedikit dengan hanya $1,9 \%$. Latar belakang pendidikan SMP juga masih dapat ditemui yaitu sebesar $3,8 \%$ pegawai (Tabel 1).
Koefisien korelasi antara structural social capital, relational social capital dan cognitive social capital dengan kinerja pegawai adalah masing-masing sebesar 0,63; 0,64 dan 0,65. Dari keluaran tampak bahwa ketiganya (kaitan antara structural, relational dan cognotive social capital dengan kinerja pegawai) mempunyai nilai signifikansi 0,00 dan lebih kecil dari nilai $\alpha=0,01$ ( $p<$ $0,01)$. Dengan demikian koefisien korelasi adalah bermakna secara statistik. Adapun koefisien determinasi adalah masing-masing sebesar 0,$40 ; 0,41$ dan 0,43 . Dengan nilai signifikansi yang lebih kecil daripada $\alpha=0,01 \quad(p<0,01)$ dapat dinyatakan bahwa koefisien determinasi ketiganya bermakna secara statistik (Tabel 2).

Selanjutnya hasil pengujian anova dengan menggunakan uji $\mathrm{F}$ masing-masing memperlihatkan nilai sebesar 33,69; 35,52 dan 37,16 dengan ketiganya memiliki nilai signifikansi 0,00 ( $p<$ $0,01)$. Dari hasil ini tampak koefisien regresi bermakna secara statistik. Hasil penghitungan koefisien regresi menunjukkan nilai koefisien Beta masing-masing sebesar 0,63 ; 0,64 dan 0,65 dengan nilai signifikansi $0,01 \quad(p<0,01)$. Menyimak hasil ini dapat dinyatakan bahwa koefisien Beta bermakna secara statistik, yang berarti structural social capital, relational social capital dan cognitive social capital berpengaruh terhadap kinerja pegawai.

Tabel 2. Pengaruh Dimensi-Dimensi Social Capital dengan Kinerja Pegawai pada BPJS Kesehatan Cabang Pasuruan

\begin{tabular}{lcccccc}
\hline $\begin{array}{l}\text { Dimensi Social } \\
\text { Capital terhadap } \\
\text { Kinerja Pegawai }\end{array}$ & Mean & $\begin{array}{c}\text { Standar } \\
\text { Deviasi }\end{array}$ & $\begin{array}{c}\text { Koefisien } \\
\text { korelasi }\end{array}$ & $\begin{array}{c}\text { Koefisien } \\
\text { Determinasi }\end{array}$ & Nilai F & Koefisien Beta \\
\hline Structural & 23,54 & 2,22 & $0,63(\mathrm{Sig}=0,00)$ & 0,40 & $33,69(\mathrm{Sig}=0,00)$ & $0,63(\mathrm{Sig}=0,00)$ \\
Relational & 25,99 & 2,54 & $0,64(\mathrm{Sig}=0,00)$ & 0,41 & $35,52(\mathrm{Sig}=0,00)$ & $0,64(\mathrm{Sig}=0,00)$ \\
Cognitive & 8,70 & 0,92 & $0,65(\mathrm{Sig}=0,00)$ & 0,43 & $37,16(\mathrm{Sig}=0,00)$ & $0,65(\mathrm{Sig}=0,00)$ \\
\hline
\end{tabular}

Sumber : Data Primer, 2015

Tabel 3. Pengaruh Unidimensi Social Capital dengan Kinerja Pegawai pada BPJS Kesehatan Cabang Pasuruan

\begin{tabular}{ccccccc}
\hline $\begin{array}{c}\text { Unidimensi } \\
\begin{array}{c}\text { Social Capital } \\
\text { terhadap Kinerja } \\
\text { Pegawai }\end{array}\end{array}$ & Mean & $\begin{array}{c}\text { Standar } \\
\text { Deviasi }\end{array}$ & $\begin{array}{c}\text { Koefisien } \\
\text { korelasi }\end{array}$ & $\begin{array}{c}\text { Koefisien } \\
\text { Determinasi }\end{array}$ & Nilai F & Koefisien Beta \\
\hline Social Capital & 58,21 & 5,35 & $0,68(\mathrm{Sig}=0,00)$ & 0,46 & $43,23(\mathrm{Sig}=0,00)$ & $0,68(\mathrm{Sig}=0,00)$ \\
\hline
\end{tabular}

Sumber : Data Primer, 2015 
Sementara itu, berdasarkan hasil uji regresi antara dimensi-dimensi social capital yang disatukan (unidimensi) dengan kinerja pegawai didapati bahwa koefisien korelasi antara social capital dengan kinerja pegawai adalah sebesar 0,68 . Nilai signifikansi adalah sebesar 0,00 dan lebih kecil dari nilai $\alpha=0,01(p<0,01)$. Dengan demikian koefisien korelasi adalah bermakna secara statistik. Adapun koefisien determinasi adalah sebesar 0,46. Dengan nilai signifikansi yang lebih kecil daripada $\alpha=0,01(p<0,01)$ dapat dinyatakan bahwa koefisien determinasi bermakna secara statistik (Tabel 3).

Merujuk hasil pengujian anova dengan menggunakan uji $\mathrm{F}$ memperlihatkan nilai 43,23 dan nilai signifikansi $0,00(p<0,01)$. Dari hasil ini tampak koefisien regresi bermakna secara statistik. Hasil penghitungan koefisien regresi menun- si 0,00 . Hanya saja hasil uji ini tidak menunjukkan signifikansi pada koefisien Beta structural social capital bernilai 0,19 dengan siginifikasi $0,40(p>0,01)$, relational social capital bernilai 0,24 dengan siginifikasi $0,26(\mathrm{p}>0,01)$ dan cognitive social capial bernilai 0,32 dengan signifikasi $0,09$ ( $p>0,01)$. Dengan demikian, dimensi-dimensi structural social capital, relational social capital dan cognitive social capital secara bersama-sama tidak berpengaruh terhadap kinerja pegawai (Tabel 4).

\section{PEMBAHASAN}

Berdasakan hasil penelitian yang telah dilakukan dapat diketahui bahwa structural social capital pada BPJS Kesehatan Cabang Pasuruan memiliki pengaruh positif terhadap kinerja

Tabel 4. Pengaruh Multidimensi Social Capital dengan Kinerja Pegawai pada BPJS Kesehatan Cabang Pasuruan

\begin{tabular}{|c|c|c|c|c|c|c|}
\hline \multirow{2}{*}{$\begin{array}{l}\text { Multidimensi Social } \\
\text { Capital terhadap } \\
\text { Kinerja Pegawai }\end{array}$} & \multicolumn{6}{|c|}{ Hasil Analisis Statistik } \\
\hline & Mean & $\begin{array}{c}\text { Standar } \\
\text { Deviasi }\end{array}$ & $\begin{array}{c}\text { Koefisien } \\
\text { korelasi }\end{array}$ & $\begin{array}{c}\text { Koefisien } \\
\text { Determinasi }\end{array}$ & Nilai $F$ & $\begin{array}{c}\text { Koefisien } \\
\text { Beta }\end{array}$ \\
\hline Structural Social Capital & 44,33 & 4,48 & $\begin{array}{c}0,63 \\
(\mathrm{Sig}=0,00)\end{array}$ & 0,48 & $\begin{array}{c}14,59 \\
(\operatorname{Sig}=0,00)\end{array}$ & $\begin{array}{c}0,19 \\
(\operatorname{Sig}=0,40)\end{array}$ \\
\hline Relational Social Capital & 23,54 & 2,21 & $\begin{array}{c}0,64 \\
(\operatorname{Sig}=0,00)\end{array}$ & 0,48 & $\begin{array}{c}14,59 \\
(\operatorname{Sig}=0,00)\end{array}$ & $\begin{array}{c}0,24 \\
(\mathrm{Sig}=0,26)\end{array}$ \\
\hline Cognitive Social Capial & 8,69 & 0,91 & $\begin{array}{c}0,65 \\
(\operatorname{Sig}=0,00)\end{array}$ & 0,48 & $\begin{array}{c}14,59 \\
(\operatorname{Sig}=0,00)\end{array}$ & $\begin{array}{c}0,32 \\
(\operatorname{Sig}=0,09)\end{array}$ \\
\hline
\end{tabular}

Sumber : Data Primer, 2015

jukkan nilai koefisien Beta sebesar 0,68 dengan nilai signifikansi $0,00(\mathrm{p}<0,01)$. Menyimak hasil ini dapat dinyatakan bahwa koefisien Beta bermakna secara statistik, yang berarti structural social capital, relational social capital dan cognitive social capital secara bersama-sama berpengaruh terhadap kinerja pegawai.

Ketika dilakukan uji regresi dengan pendekatan multidimensi, terdapat perbedaan hasil dengan pengujian yang menggunakan pendekatan unidimensi. Memang untuk koefisien korelasi masih menunjukkan adanya signifikansi pada ketiga dimensi social capital, yaitu structural $(0,63$ dengan signifikasi 0,00$)$, relational $(0,64$ dengan signifikasi 0,00$)$ dan cognitive $(0,65$ dengan signifikasi 0,00 ). Begitu pula dengan uji $\mathrm{F}$, terdapat hasil yang signifikan untuk ketiga dimensi social capital, yaitu dengan nilai 14,59 pada signifikan- pegawai. Dengan demikian, semakin baik kondisi structural social capital yang ada dalam BPJS Kesehatan Cabang Pasuruan, maka akan membuat kinerja pegawai semakin baik pula. Hal ini dilatarbelakangi dengan hasil koefisien determinasi yang menunjukan nilai structural social capital memengaruhi kinerja pegawai sebesar 0,39 atau dengan presentase sebesar $39 \%$. Nilai tersebut, bersama koefisien Beta $(0,63)$ menunjukkan kekuatan pengaruh yang diberikan structural social capital terhadap kinerja pegawai.

Temuan dalam penelitian ini yang membuktikan adanya pengaruh dimensi structural social capital terhadap kinerja pegawai tampak sejalan dengan beberapa hasil penelitian. Didapati adanya pengaruh dimensi structural social capital terhadap kinerja pegawai pada area e-bisnis. Bahwa dalam pengembangan sistem informasi yang tang- 
guh, salah satu dimensi social capital ini mempunyai keterpengaruhan yang cukup tinggi terhadap kinerja pegawai baik secara substansial maupun secara simbolis..$^{13}$ Demikian pula ditemukan adanya pengaruh dimensi structuralsocial capital pada kinerja tugas tridarma perguruan tinggi. Dosen yang memiliki jejaring sosial yang tinggi dapat memengaruhi kinerja pendidikan, penelitian dan pengabdian kepada masyarakat. ${ }^{14}$ Pada BPJS Kesehatan Cabang Pasuruan penguatan kerangka struktural ini dapat dilihat pada terdapatnya pola supervisi yang jelas di setiap unit kerja. Dengan interaksi sosial yang fleksibel akan tampak adanya kedekatan antar pegawai maupun dengan pimpinan. ${ }^{15}$

Fenomena ini sangat menarik bila dikaitkan dengan konsep power distance. ${ }^{16}$ Power distance atau jarak kekuasaan merupakan tingkat kepercayaan atau penerimaan terhadap suatu kekuasaan yang tidak seimbang dari khalayak. Sebuah budaya yang menganggap pimpinan lebih superior dibandingkan dengan bawahan karena status sosial, jender, ras, usia, pendidikan dan latar belakang lainnya. Terdapat kesenjangan komunikasi, partipasi bawahan rendah, kontrol yang ketat terhadap bawahan, keputusan yang dibuat hanya oleh pimpinan adalah sebagian dari karakteristik jarak kekuasaan di negara berkembang. ${ }^{17}$ Indonesia sebagai salah satu negara yang diteliti berada pada urutan 8-9 dari 53 negara yang menunjukkan jarak kekuasaan masih tinggi. Penelitian tersebut terbantahkan dalam pengujian ini.

Berdasarkan hasil penelitian dapat diketahui bahwa relational social capital dapat memengaruhi kinerja pegawai. Dengan demikian, bisa dinyatakan bahwa relational social capital pada BPJS Kesehatan Cabang Pasuruan memiliki pengaruh positif terhadap kinerja pegawai yang ada di dalamnya.

Dengan semakin baik kondisi relational social capital yang terdapat di dalam BPJS Kesehatan Cabang Pasuruan akan membuat kinerja pegawai semakin lebih baik. Kekuatan relational social capital dalam memengaruhi kinerja pegawai dapat diketahui melalui nilai koefisien Beta sebesar 0,64 dan nilai koefisien determinasi yang sebesar 0,40 atau persentase kekuatan relational social capital dalam memengaruhi kinerja pegawai adalah sebesar $40 \%$.
Hasil pembuktian ini sesuai dengan penelitian tentang pengaruh social capital pada kinerja sektor perbankan. ${ }^{18}$ Bahkan dimensi relational social capital berpengaruh terhadap kinerja pegawai bank, terutama dalam aspek kepercayaan. Kepercayaan di antara anggota organisasi memupuk keyakinan bahwa mereka mengejar tujuan yang sama dan berbagi informasi untuk tujuan ini. Karakteristik ini menunjukkan adanya upaya berbagi informasi, dukungan rekan kerja dan mengkoordinasikan upaya-upaya yang pada gilirannya menghasilkan efektivitas dan kinerja organisasi. Sebaliknya pegawai yang tidak percaya satu sama lain cenderung berperilaku oportunistik dan mengejar kepentingan pribadi mereka belaka. ${ }^{19}$

Pada BPJS Kesehatan Cabang Pasuruan, pengaruh dimensi relational social capital didukung oleh kenyataan adanya $82,7 \%$ pegawai yang mempunyai masa kerja tidak lebih dari 8 tahun serta dominan pada hampir semua unit kerja. Bahwa sebagai pegawai yang relatif baru dan berangkat dengan riwayat sepadan, mereka cenderung mempunyai tingkat loyalitas cukup tinggi, bukan hanya pada pekerjaan, tetapi juga pada kesetiakawanan. Kompetisi diantara mereka belum menggejala sehingga bisa jadi mereka akan lebih mudah membangun kepercayaan bersama. ${ }^{20}$ Hasil penelitian ini juga menunjukkan bahwa $\operatorname{cog}$ nitive social capital dapat memengaruhi kinerja pegawai. Dengan demikian dapat diartikan bahwa cognitive social capital memiliki pengaruh positif terhadap kinerja pegawai pada BPJS Kesehatan Cabang Pasuruan.

Pengaruh cognitive social capital ini ditunjukkan dengan nilai koefisien Beta 0,65 serta nilai koefisien determinasi yaitu sebesar 0,41 . Hasil tersebut dapat berarti bahwa presentase kekuatan cognitive social capital dalam memengaruhi kinerja pegawai pada BPJS Kesehatan Cabang Pasuruan secara positif adalah sebesar $41 \%$. Hasil penelitian ini setidaknya memiliki arah yang sama dengan temuan yang menunjukkan bahwa dimensi cognitive social capital berpengaruh terhadap kinerja pegawai bank. ${ }^{21}$ Adapun kesamaan bahasa, ungkapan serta nilai-nilai sesama rekan kerja telah membentuk tafsir lingkungan tempat kerja yang identik dan bila memiliki perbedaan pengetahuan terkait tugas pekerjaan, mereka mampu untuk menggabungkannya. ${ }^{22}$ Pada BPJS Kesehat- 
an Cabang Pasuruan, setiap pegawai harus dapat menjiwai visi perusahaan. Dengan kesamaan dalam mempersepsikan visi ini, ditunjang dengan tingkat rasionalitas yang cukup tinggi yang ditandai $82,7 \%$ pegawai adalah berpendidikan diploma 3 ke atas, maka pengaruh dimensi cognitive social capital terhadap kinerja pegawai dapat dipahami. Social capital terdiri dari 3 (tiga) dimensi yaitu structural social capital, relational social capital dan cognitive social capital. Berdasarkan hasil uji regresi diketahui bahwa secara bersama-sama ketiga dimensi tersebut (unidimensi) dapat memengaruhi secara positif kinerja pegawai pada BPJS Kesehatan Cabang Pasuruan.

Kondisi ini terlihat dari nilai koefisien Beta sebesar 0,68 dan koefisien determinasi yang menunjukkan nilai 0,46. Dengan demikian dapat diketahui bahwa social capital yang terdapat dalam BPJS Kesehatan Cabang Pasuruan ini memengaruhi kinerja pegawai sebesar $46 \%$. Memang keterpengaruhannya tidak mutlak karena masih ada $54 \%$ pengaruh yang bukan berasal dari variabel social capital. Secara klasik disadari bahwa kinerja merupakan faktor dari motivasi dan kemampuan. Dengan demikian bisa jadi yang memengaruhi kinerja pegawai selain social capital adalah aspek motivasi dan kemampuan. Namun, demikian ada penegasan yang menunjukkan bahwa kesempatan, motivasi dan kemampuan harus hadir untuk mengaktifkan social capital. Seorang yang tanpa adanya kesempatan terikat dalam jejaring penerima, tanpa motivasi untuk berkontribusi atau tanpa kemampuan yang diperlukan tidak akan menjadi sumber social capital. Kurangnya salah satu dari ketiga faktor tersebut akan merusak kekuatan social capital. ${ }^{5}$ Bagaimanapun, motivasi dan kemampuan berperan membawa ke arah mana perilaku pegawai dipusatkan. Proses penentuan arah tersebut diupayakan dan dicapai secara beriringan dengan faktor-faktor social capital yang melingkupinya. ${ }^{23}$

Manakala ketiga dimensi social capital diperlakukan dalam tataran multidimensi, tampak bahwa structural social capital, relational social capital dan cognitive social capital tidak mempunyai pengaruh terhadap kinerja pegawai. Sesungguhnya kenyataan ini sejalan dengan beberapa hasil penelitian yang menyebut bahwa ketiga dimensi ini memang tidak bersifat mutually exclusive, sehingga ketiganya highly interrelated. Mutually exclusive adalah dua atau lebih kejadian yang saling meniadakan atau tidak dapat terjadi secara bersama-sama. Artinya, kejadian yang satu akan sekaligus meniadakan kemungkinan terjadinya kejadian yang lain. ${ }^{21,24}$ Memilik fakta tersebut, dapat dikemukakan bahwa variabel social capital merupakan kumpulan dari dimensi-dimensi yang bersifat unidimensional. Hal ini terlihat dari hasil analisis penelitian bahwa ketika dimensi-dimensi tersebut diperlakukan sebagai variabel tidak dapat memengaruhi kinerja pegawai pada BPJS Kesehatan Cabang Pasuruan. Tampak bahwa social capital sebagai satu kesatuan tidak dapat diposisikan pada dimensinya masing-masing. Social capital harus diletakkan pada posisi sebagai suatu kerangka dimensi yang utuh tak terpisahkan.

\section{KESIMPULAN DAN SARAN}

Dimensi structural social capital, relational social capital maupun cognitive social capital secara terpisah mempunyai pengaruh yang positif terhadap kinerja pegawai BPJS Kesehatan Cabang Pasuruan. Interaksi sosial, tingkat kepercayaan serta kesamaan dalam mengartikan visi perusahaan dipandang merupakan aspek yang dapat mewarnai kinerja pegawai. Ketika ketiga dimensi ini disatukan (unidimensi) masih tampak adanya pengaruh terhadap kinerja pegawai. Namun, manakala ketiga dimensi social capital tersebut diperlakukan secara multidimensi tidak diperoleh hasil keterpengaruhan yang signifikan. Social capital sebagai satu kesatuan tidak dapat diposisikan pada dimensinya masing-masing, tetapi harus diletakkan sebagai sebuah kerangka dimensi yang utuh. Bahwa penelitian ini menegaskan adanya pengaruh dimensi-dimensi social capital terhadap kinerja pegawai. Akan tetapi sebegitu jauh belum mengkaji aspek lain yang bersama-sama social capital memengaruhi kinerja pegawai. Untuk maksud tersebut perlu dilakukan penelitian yang menampilkan variable-variabel lain dalam kaitannya dengan kinerja pegawai seperti motivasi, kemampuan maupun peluang. Selanjutnya disarankan kepada BPJS Kesehatan Cabang Pasuruan untuk mengemas dimensi-dimensi social capital dalam praktik keseharian sebagai upaya meningkatkan dan mempertahankan kinerja pegawainya. 


\section{UCAPAN TERIMA KASIH}

Penghargaan yang tinggi disampaikan untuk segenap saran dan masukan dalam penulisan penelitian ini yang diberikan oleh Bapak Mochammad Djudi Drs., M.Si. dan Bapak Mohammad Iqbal MIB., DBA., pakar-pakar Administrasi Bisnis dan Sumber Daya Manusia dari Universitas Brawijaya, serta Bapak Agus Widjanarko, SKM., M.Kes., AAK., seorang praktisi kesehatan masyarakat dan asuransi kesehatan yang juga merupakan Penanggung Jawab Perhimpunan Sarjana Kesehatan Masyarakat Indonesia (PERSAKMI) Kota Pasuruan. Tentu rasa terima kasih patut dihaturkan kepada Ibu Susilawati Agustin, dr., MM., AAK., Kepala BPJS Kesehatan Cabang Pasuruan yang telah berkenan menyediakan institusinya untuk dijadikan lahan penelitian.

\section{DAFTAR PUSTAKA}

1. Gilley Ann, Jerry W.G., Scott A.Q., and Pamela D. The Praeger Handbook of Human Resource Management Volume 1 and 2. Westport: Greenwood; 2009. pp. 438.

2. Weaver,R.D., andHabibov, N. Sosial Capital, Human Capital, and Economic Well-Being In The Knowledge Economiy: Results From Canada's General Social Survey. Journal of Sociology \&Social Welfare. 2012;39(2):31-53

3. Tsang, K-K. School Social Capital and School Effectiveness. Education Journal. 2010;37(12):119-136.

4. Ernstmann, N., Ommen, O., Driller, E., Kowalski, C., Neumann, N., Bartholomeyczik, S., and Pfaff, H.Social Capital and Risk Management in Nursing. J Nurs Care Qual. 2009;24(4):340-347.

5. Piskorski, M.J., and Gorbatai, A. Testing Coleman's Social-Norm Enforcement Mechanism: Evidence from Wikipedia: Harvard Business School Working Paper. 2013;11(055).

6. Sultanah, A., Sobia, I., Kamran, A., and Nasir, M. Impact of Training On Employee Performance: A Study of Telecommunication Sector In Pakistan. Interdisciplinary Journal of Contemporary Research In Business. 2012;4(6):646-661.

7. Syauta, J.H., Eka, A.T., Margono, S., and Solimun.The Influence of Organizational Cul- ture, Organizational Commitment to Job Satisfaction and Employee Performance (Study at Municipal Waterworks of Jayapura, Papua Indonesia). International Journal of Business and Management Invention. 2012;1(1):69-76.

8. Jeong, S.W. Impacts of Social Capital on Motivation, Institutional Environment, and Consumer Loyalty toward a Rural Retailer [Dissertations]. United States: Graduate School of The Ohio State University; 2011.

9. Abbasi, A., Liaquat, H., and Rolf, W. Social Capital and Individual Performance: A Study of Academic Collaboration. Journal of The Association for Information Science and Technology. 2011;63(12):1-18.

10. Creswell, J.W. Research Design: Qualitative, Quantitative, and Mix Methods Approaches. 3rd Ed. California: Sage Publication; 2009. pp. 18-19 and 156.

11. Zikmund, W.G., Barry, J.B., Jon, C.C., and Mitch, M. Business Research Methods. $9^{\text {th }}$ Edition. Ohio: South-Western; 2013. pp. 554.

12. Hair, J.F., William, C.B., Barry, J.B., and Rolph, E.A. Multivariate Data Analysis: A Global Perspective. $7^{\text {th }}$ Edition. New Jersey: Pearson Education; 2009. pp. 151.

13. Liu, H., Weiling, K., Kwok-Kei, W., and Yaobing, L. The Effects of Social Capital on Firm Substantial and Symbolic Performance In The Context of E-Business. School of Management University of Sciences of China: Working Paper; 2014.

14. Fauzan, M. Peningkatan Kinerja Dosen Berbasis Modal Sosial dan Dukungan Organisasional Di PTS Kota Semarang. Jurnal Bisnis dan Ekonomi (JBE). 2012;19(2):188-202.

15. Vandaie, R. Developing A Framework to Describe the Interaction of Social and Intellectual Capital In Organizations. Journal of Knowledge Management Practice. 2007;8(1).

16. Hofstede, Geert. Demensionalizing Cultures: the Hofstede Model In Context. Online Readings In Psyhology and Culture. 2011;2(1):126.

17. Khatri,N. Consequences of Power Distance Orientation In Organisations. The Journal ofBusiness Perspective. 2009;13(1):1-9.

18. Ehman, A., Erlan B., Hidayet, T., and Sedat, K. Analysis of Relationship Among Social 
Capital, Organizational Justice and Performance with Structural Equation Model: The Case of Banking Sector. International Review ofSocial Sciences. 2014;2(7):207-220.

19. Leana, C.R.,and Pil, F.K. Social Capital and Organizational Performance: Evidence from Urban Public Schools. Organizational Science. 2006;17(3):353-366.

20. Turner, J.Social Capital: Measurement, Dimensional Interactions, and Performance Implications [Dissertations]. United States: Clemson University; 2011.

21. Ariani, D.W. The Relationship between Social Capital, Organizational Citizenship Behaviors, and Individual Performance: An Empirical Study from Banking Industry In Indonesia. Journal of Management Research.
2012;4(2):226-241.

22. Blad, Sofie. The Influence of Social Aspects On New Venture Creation - A Qualitarive Study On the Role of Entrepreneurs' and Entrepreneuses' Social Capital and Social Competence In The Start-Up Phase [Master Thesis]. Finland: Swedish School Of Economics and Business Administration; 2008.

23. Uzonna, U.R. Impact Of Motivation On Employees Performance: A Case Study of Creditwest Bank Cyprus. Journal of Economics and International Finance. 2013;5(5):199-211.

24. Syed, A.A., Sanjeev, B., and Anjali, S. Social Capital Framework: Examining the Online Public Conversation On Indian Discussion Board. AIMA Journal of Management \& Research. 2014;8(1):1-23. 